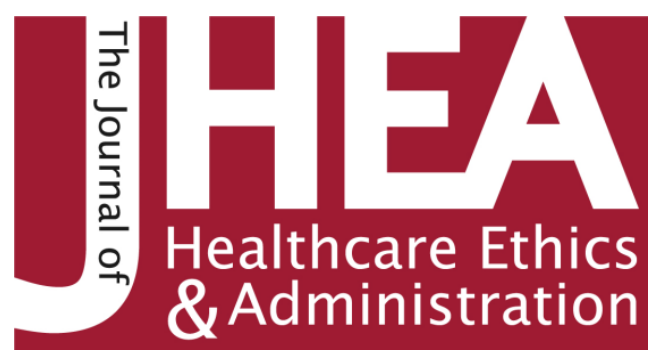

\title{
MEDICAL COMMENTARY
}

\section{Limited Medical Resources}

This article appeared originally in The Internet Journal of Catholic Bioethics (Spring 2009)

MARK C. AITA, S.J., M.D.

The Institute of Clinical Bioethics, Saint Joseph's University, Philadelphia, Pennsylvania, U.S.A.

${ }^{\star}$ Address correspondence to: The Institute of Clinical Bioethics, Saint Joseph’s University, 5600 City Ave, Philadelphia, Pennsylvania 19131, U.S.A. 


\section{MEDICAL COMMENTARY}

\section{Limited Medical Resources}

This article appeared originally in The Internet Journal of Catholic Bioethics (Spring 2009)

MARK C. AITA, S.J., M.D.

The Institute of Clinical Bioethics, Saint Joseph's University, Philadelphia, Pennsylvania, U.S.A.

History, physical examination, diagnosis, and treatment. Every medical student knows these basic sequential steps in the evaluation of a new patient. The volunteer medical team which came across the young Haitian boy in this case study began their evaluation with step 3 (diagnosis) before completing steps 1-2. Surely a life of staring at nothing but the ground is a scary and lonely experience for the young lad. A compassionate physician would get down on his knees and look into the child's eyes with a reassuring smile, chat and show interest in him, then tell him a story that would make him laugh. The doctors in this case study speak with the parents, but there's no evidence they ever spoke with the child. They didn't even ask the child if he was in pain. As we'll see, back pain and other potential symptoms of the boy's medical problem should be explored before making a decision to subject him to radical corrective surgery.

A healthy human spine has three gradual curves. The neck and lower back curve gently inward. This is called lordosis. The thoracic outward curve, called kyphosis, gives the mid back its slightly rounded appearance. These normal curves help the spine absorb forces from gravity and daily activities, such as lifting.

The angle of normal kyphosis in the thoracic spine varies. During the growth years a normal curve is 25-40 degrees. If the curve angles more than 40 degrees, doctors consider the kyphosis a deformity. An exaggerated thoracic kyphosis exceeding 45 degrees is called Scheuermann's disease. Since the young lad in the case study walks with his head hung as low as his waist, he surely has severe thoracic kyphosis with a curvature exceeding 90 degrees.

The back bones which protect the spinal cord are called the vertebrae. Vertebral bodies are like blocks stacked upon one another and separated by spongy cushions called intervertebral discs. The discs are attached to one another in the back by a ring of bone called the posterior vertebral arch which surrounds and protects the spinal cord. In Scheuermann's disease the front of the vertebral body becomes wedge-shaped, likely from abnormal growth. The triangular wedge increases the outward bend in the midback. Vertebral bodies are attached in front by the anterior longitudinal ligament. In Scheuremann's disease the ligament thickens and pulls the anterior vertebral wedges closer together, further increasing the outward bend.

Scheuremann's disease is often asymptomatic, but low back pain is common, especially in young active boys. Before describing the severe potential complications, it is important to emphasize that they are indeed rare. The spinal cord may be affected by two mechanisms. First, severe kyphosis stretches the spinal cord over the top of the thoracic curve yet injury to the cord is rare. Second, there is some risk of disc herniation in which extruded disc material squeezes and puts pressure on the spinal cord and spinal nerves. The symptoms that may result from these complications include back pain, leg weakness, and very rarely loss of bowel and bladder function. When the angle of kyphosis exceeds 100 degrees, the sharply bent spine puts pressure on the heart, lungs and abdomen. This may cause fatigue, shortness of breath, chest pain and loss of appetite.

Given the rarity of severe symptomatology, a thorough history and physical examination are essential in the evaluation of a child with Scheuremann's kyphosis. Unfortunately, the volunteer medical team looks upon the child more as a pathological specimen than as a human person. How he feels physically and emotionally and how he relates to his environment would be an appropriate line of questioning. Is he in pain? Is he eating well and gaining weight? Can he move around well enough to play and have fun with his friends? How is he doing at school? Does he seem to be a happy child?

A fundamental principle of ethics is non-malfeasance (do no harm). If this young lad is coping with his back deformity, is it wise to subject him to surgery with $30-50 \%$ mortality rate and even greater risk of total paralysis and dependence on a respirator? 
The anesthesiologist is wise to throw up the red flag in this case. Only salvage, life and death surgery would warrant such a risk. And surgical correction of Scheuremann's deformity does not rank in this category. 